Erwin J. O. Kompanje

\title{
The worst is yet to come. Many elderly patients with chronic terminal illnesses will eventually die in the emergency department
}

Received: 8 January 2010

Accepted: 14 January 2010

Published online: 13 March 2010

(C) The Author(s) 2010. This article is published with open access at Springerlink.com

This editorial refers to the article available at: doi:10.1007/s00134-010-1800-1.

E. J. O. Kompanje (®)

Department of Intensive Care,

Erasmus MC University Medical Center,

P.O. Box 2040, 3000 CA Rotterdam, The Netherlands

e-mail: erwinkompanje@me.com

In the western world, two important life events, birth and death, most often occur in hospitals. Among professional caregivers and the lay public, there is a growing concern that excessive and scarce resources are used to provide unwanted and futile life-sustaining medical treatment for patients at the end of their life. Concerns that death is unnecessarily prolonged by technical and pharmacological interventions are frequently heard. Consequently, decisions to forego (further) treatment are made more often.

Most literature on withholding and withdrawing treatment in the acute-care setting is reported from intensive care units (ICU). Dying on an ICU is in many western countries preceded by a treatment-limiting decision. Some report that this occurs in no less than $80 \%$ of all deaths on ICUs. Withdrawing treatment, such as mechanical ventilation, in patients with severe organ failure, almost always results in death within hours. In this sense death on the ICU can be planned. So, physicians can make the transition from attempting to cure serious conditions and prolong life to providing comfort care and allowing death with dignity in a steady way. Physicians and nurses on the ICU can anticipate distressing symptoms that can occur after withdrawal of life-sustaining treatment. With an ageing population, and an increasing number of patients with serious comorbidity, decisions to withhold and withdraw treatment will need to be made more often. The decision to withdraw treatment is never made hastily, and is never easy.

In the perception of some people, in the emergency department the decision to withhold or withdraw treatment is made because of failure of adequate aggressive therapy or a rapid and fatal deterioration of the condition of the patient. However, in 2002 an article by Tardy et al. [1] was published in this journal with the title 'Death of terminally ill patients on a stretcher in the emergency department: a French speciality?'. They reported that more than a third of the patients who died in the emergency department were patients in a terminal stage of chronic disease. These patients were suffering from a terminal malignancy, chronic neurological conditions or an end-stage cardiopulmonary condition. They were expected to die soon from their terminal disease, but were brought to the emergency department for events related to the evolution of their disease. As the authors mentioned in their discussion, the emergency department was for these patients not a site of emergency care but a place for dying. This is a questionable development, as the emergency department is not the most appropriate place for adequate end-of-life care which should take place in a quiet and peaceful area. This gives rise to ethical and practical problems for physicians and nurses working in these emergency departments.

In this issue of Intensive Care Medicine, Le Conte et al. [2] provide important additional data to the literature on dying in the emergency department. After a single-centre pilot study, published in 2004 [3], they undertook a 4-month prospective survey in 174 emergency departments in France and Belgium to investigate the cases of patients who died there and the decisions and arguments that limited further treatment. They conducted an analysis of 2,420 patients. Most of these patients were of advanced age with a 
mean age of 77 years, $46 \%$ had a functional limitation and no less than $82 \%$ suffered from a chronic underlying disease. After admission, life support treatment was started in $74 \%$, after which a decision to withhold or withdraw further life-sustaining treatment was taken before death in $79 \%$. The median time between admission and the decision to withdraw life-sustaining treatment in this cohort was $2 \mathrm{~h}$. This is the image of an ageing society in which terminally ill patients are transported to a hospital to die.

The criteria used to justify limiting life-sustaining treatment in 1,907 patients in this study were the medical condition on admission in 77\%, the expected irreversibility of the acute condition in the first $24 \mathrm{~h}$ in $54 \%$ and the absence of improvement after initiation of acute treatment in $26 \%$. These are understandable and reasonable criteria. More questionable are criteria such as 'age' (39\%), 'previous functional limitation' (38\%), 'underlying chronic disease' (35\%), 'recovery but expected quality of life unacceptably poor' $(25 \%)$ and 'underlying disease expected to be fatal in the following 6 months' $(20 \%)$. The use of these criteria is especially worrying, in view of the fact that the median time between admission and the decision to limit further treatment was $2 \mathrm{~h}$. Are physicians able to get a clear picture of the quality of life of a patient before admission and are they able to predict the prognosis of a chronic condition over the next 6 months? In a prospective cohort study conducted in The Netherlands, more than $90 \%$ of physicians " prognoses in terminally ill (mostly noncancer) patients who died within 7 days were accurate. But for a longer period of time, their predictions became inaccurate. Predictions were accurate in only $16 \%$ of patients who were expected to die within 821 days, and in $13 \%$ of patients expected to die within 22 42 days [4]. This is also reflected in a study in which actual survival of 216 cancer patients receiving palliative care was related to subjective prediction of survival. Two physicians (one an oncologist) estimated the prognosis correctly in 55\% and $61 \%$. The institutional tumour board estimated the prognosis correctly in 63\% [5]. A poor prognosis or impending death is sometimes incorrectly assumed, making the individual clinical course unexpected [6]. When in such cases making decisions to withhold or withdraw treatment in accordance with the expected prognosis could lead to medical wrongdoing.

Are only the physicians to blame for decisions that seem not to be based on sound criteria. Yes and no. More important is that the terminally ill patients who die on a stretcher on French emergency departments should not be there in the first place. Family physicians should provide basic medical care and palliative care in the patient's home and they should only serve as a gateway to specialized care for more complex problems. End-of-life care for patients in the terminal stage of their chronic illness should be provided in the home situation by family physicians, homecare nurses and informal (family) care-givers. Most people prefer to die in their own home instead of in a hospital [7]. However, patients are often transported to hospital in the terminal stage of their illness due to lack of professional care in the home situation and at the request of heavily burdened relatives. Patients and their relatives often think that professional care-givers in an institutional setting would provide the best treatment of terminal symptoms. But this assumption is probably more a reflection of access to and the quality of end-of-life care given by family physicians and home-care nurses in the outpatient setting. Additionally, access to informal care support is invariably found to be a strong determinant for patients being able to die in their own bed at home [8].

The findings described by Le Conte et al. are at least disturbing. That many elderly patients die from a chronic disease in the emergency department is probably a sign of failure of adequate outpatient care in an ageing society. The absolute number of older people with chronic conditions and limitations is increasing in most countries in the western world; we must prepare ourselves for the worst yet to come.

Open Access This article is distributed under the terms of the Creative Commons Attribution Noncommercial License which permits any noncommercial use, distribution, and reproduction in any medium, provided the original author(s) and source are credited.

\section{References}

1. Tardy B, Venet C, Zeni F, Berthet $\mathrm{O}$, Viallon A, Lemaire F, Bertrand JC (2002) Death of terminally ill patients on a stretcher in the emergency department: a French speciality? Intensive Care Med 28:1625-1628
2. Le Conte P, Riolet D, Batard E, Volteau C, Giraudeau B, Arnaudet I, Labestire L, Levraut J, Lauque D, Piva C, Schmidt J, Thys F, Trewick D, Potel G (2010) Death in emergency departments: a multicenter cross-sectional survey with analysis of withholding and withdrawing lifesupport. Intensive Care Med. doi:10.1007/s00134-010-1800-1
3. Le Conte P, Baron D, Trewick D (2004) Withholding and withdrawing lifesupport therapy in an emergency department: prospective survey. Intensive Care Med 30:2216-2221

4. Brandt HE, Ooms ME, Ribbe MW, Van der Wal G, Deliens L (2006) Predicted survival vs. actual survival in terminally ill noncancer patients in Dutch nursing homes. J Pain Symptom Manage 32:560-566 
5. Gripp S, Moeller S, Bölke E, Schmitt G, Matuschek C, Asgari S, Asgharzadeh F, Roth S, Budach W, Franz M, Willers R (2007) Survival prediction in terminally ill cancer patients by clinical estimates, laboratory tests, and self-rated anxiety and depression. J Clin Oncol 25:3313-3320
6. Wijnia JW, Corstiaensen JPM (2008) A poor prognosis: guide or misleading? Am J Hosp Palliat Med 25:5-8

7. Higgison IJ, Sen-Gupta GJA (2000) Place of care in advanced cancer: a qualitative systematic literature review of patients preferences. J Palliat Med $3: 287-300$
8. Van der Heide A, De Vogel-Voogt E, Visser AP, Van der Rijt CD, Van der Maas PJ (2007) Dying at home or in an institution: perspectives of Dutch physicians and bereaved relatives. Support Care Cancer 15:1413-1421 